\title{
Three-Pronged Innovation to Improve Care for Acute Myocardial Infarction Patients in Cuba
}

\section{By Gloria Giraldo MPH}

Coronary heart disease (CHD) is the main cause of death worldwide, killing 7 million annually and representing $12.2 \%$ of all global deaths.[1,2] This trend is expected to continue over the next two decades, with greater implications for low- and middle-income countries, where three-fourths of CHD deaths were already occurring by 2001.[3,4] CHD is the leading cause of death in Latin America and the Caribbean, and there, as well as in the Mideast and even sub-Saharan Africa, CHD deaths are expected to triple over the next 20 years.[4,5]

In Cuba, heart disease (including CHD, hypertensive heart disease, rheumatic fever and chronic rheumatic valvular disease) has been the number one cause of death since the 1970s.[6,7] By 2004 , CHD accounted for $18.8 \%$ of total deaths and $72.5 \%$ of deaths from heart disease (15,000 deaths annually).[8] CHD mortality declined slowly from 1980 through 1996 and then turned sharply downward from 1997 through 2002, representing a 35\% cumulative decline.[9] The standardized incidence rate has varied between 1.71 per 1000 individuals aged $>15$ years in 1999 and 1.55 in 2008.[10,11] Acute miocardial infarction (AMI) is a major manifestation of CHD, and several authors place AMI as the number one cause of death in Cuba.[12,13]

Cuba's experience over the last decade reveals the synergy of three innovations at work to tackle this serious health problem: domestic development of the world's first recombinant streptokinase, implementation of a primary care strategy that brings treatment to patients in pre-hospital settings, and a nascent monitoring system through a national cardiology network. Cuba's response to AMI illustrates the interface of different levels of care-emergency, primary, secondary and tertiary-to make a life-saving treatment more widely accessible in the context of the country's universal healthcare model.

\section{MANAGEMENT OF ACUTE MYOCARDIAL INFARCTION}

AMI causes permanent damage to an area of heart muscle resulting from interruption to the blood supply caused by narrowed or blocked blood vessels. Management requires rapid restoration of blood flow and mitigation of heart muscle damage, and organization of care is a vital determinant of patient outcome. [14] The challenge is to increase coverage and access to early and appropriate treatment for a wider population. This challenge provides a unique lens to look at the ubiquitous dilemma of global health inequity; specifically the issue of access to proven effective treatment. As with many other conditions, the country or even region where a person suffers an AMI determines the probability of survival.

Remarkable treatment advances have been made in the last three decades and applied with success in certain populations. The advent of intensive coronary care units and introduction of several therapeutic strategies, such as reperfusion, resulted in AMI hospital mortality rates dropping from an alarming $30 \%$ to
$40 \%$ in the 1950 s and 1960 s to less than $5 \%$ in 2006 in some developed countries, with the caveat that these rates may disguise in-country disparities.[15] Today, reperfusion is the gold standard in developed countries, its use dependent on certain and swift availability of medications (thrombolytics) or interventions such percutaneous coronary intervention ( $\mathrm{PCl}$, commonly known as coronary angioplasty).[16]

While data on treatment and outcomes of AMI patients in developing countries is scarce and mainly derived from small one-site studies rather than large epidemiological studies or registries,[17] it is clear that the more costly angioplasty is not a viable option for the majority. The World Bank's Disease Control Priorities in Developing Countries Project conducted a cost-effectiveness study comparing no treatment at all with increasingly more complex options for more standard AMI treatment in developing countriesaspirin only, and/or beta blockers, and/or reperfusion, through exclusive use of thrombolysis. Results were reported in incremental cost per quality-adjusted life-year (QALY) gained. For both aspirin and beta-blocker intervention, cost was <US $\$ 25$ for all six regions of the developing world; for streptokinase, $\$ 630-\$ 730$ across regions, compared to aspirin and beta blocker only; and for the most expensive thrombolytic (tissue plasminogen activator), about $\$ 16,000$ compared with streptokinase.[4,5] Consequently, even in use of these treatment options, great variations are expected, based on personnel training, availability of facilities, and affordability of medicines.

In Cuba's case, important strides can be observed in the central province of Cienfuegos, where the number of AMI admissions doubled over the period 1990-2003 and lethality declined by $50 \%$. Authors reporting these results suggest the decline resulted from admission of less severe cases as well as improvement in quality of care. By 2003 , the Cienfuegos provincial hospital had achieved a total thrombolysis rate of $60 \%$, and a 'door-to-needle' time of about 30 minutes for more than $90 \%$ of all AMI patients.[7] How the smallest province in a resourcepoor country achieved first-world thrombolysis rates is the story of innovation in biotechnology and health care organizationwith important lessons being applied throughout the national health system.

\section{INNOVATION No, 1: CUBAN RECOMBINANT STREPTOKINASE}

Although streptokinase was discovered in 1933, it was not until 1986 when a landmark study-the GISSI (Gruppo Italiano per la Sperimentazione della Streptochinasi nell'Infarto Miocardico) Trial-demonstrated its effectiveness, indicating that the sooner an AMI patient was admitted to a coronary care unit and the drug administered, the better the chance of recovery. Since then, numerous clinical trials have reinforced the evidence for streptokinase use.[18]

Emphasis later shifted to discovering which thrombolytic agent was the best for AMI management. Currently, in addition to 
streptokinase, recombinant tissue plasminogen activators (r-tPAs) alteplase, reteplase and tenecteplase are used in developed countries. Comparison studies have found no evidence showing clear superiority of any one of these. $[19,20]$ The main differences are associated with mode and duration of administration, and price. Because the cost of r-tPA is nearly 10-fold that of streptokinase, the latter continues to be the thrombolytic most available for millions of patients in developing countries.[18]

Even in developed countries like the United Kingdom, one study revealed that streptokinase accounted for $55 \%$ of thrombolysis application nationally, compared to alteplase 33\% and reteplase 11\%.[20] And in Latin America, a middle-income country such as Chile, which has guaranteed AMI care in the public health system since 2005, still faces the challenge of thrombolytic scarcity: r-tPA is considered too expensive and streptokinase itself is still not available in all hospitals.[21,22] Thus, even streptokinase, ranked as one of the World Health Organization's (WHO) essential drugs,[23] remains a cost-dependent option for AMI patients.

Precisely to overcome issues of availability and cost, Cuba's Center for Genetic Engineering and Biotechnology developed a domestically-produced thrombolytic, which would become the world's first recombinant streptokinase: Heberkinasa. "Its experimental use in Cuban AMI patients began 19 years ago," Dr Fidel Cáceres, associate director of the Cardiology and Cardiovascular Surgery Institute, told MEDICC Review. One early clinical study involved 224 Cuban AMI patients from 7 hospitals in 3 provinces. A randomized group of 111 was treated with intravenous Heberkinasa; the remaining 113 patients received natural streptokinase.[24] The findings revealed no significant differences in outcomes between the two groups, or regarding coronary patency, changes in hemostasis, or safety.[25]

Another major study (November 1992-May 1995) included 2923 AMI patients in 52 Cuban hospitals nationwide who received Heberkinasa. Results were compared with those of thrombolyticeligible AMI patients at the same hospitals in 1992, before streptokinase was introduced. Heberkinasa treatment reduced deaths by $28.3 \%$ (relative decrease) and $4 \%$ (absolute decrease). Intracranial hemorrhage was reported in only 9 patients (0.3\%).[26] Furthermore, a 7-year pharmacosurveillance study (July 1995July 2002) concluded that there were no new adverse events for Heberkinasa and that the nature and severity of reported events were consistent with earlier clinical trial results.[27]

Although some authors have raised questions about certain properties of recombinant streptokinase produced in developing countries,[23] Cuban scientists stand by their product and point to the clinical trials, the seven-year pharmacosurveillance study, a thrombolysis rate of approximately $56 \%$ and declining AMI lethality. Streptokinase is also being used in other clinical applications. Hemodialysis centers use a simple Heberkinasa intraluminal infusion for hemodialysis catheter malfunction to avoid definitive catheter loss and improve patient care.[28] Recombinant streptokinase is also used to treat deep-vein thrombosis and is recommended as first choice therapy for prosthetic heart valve thrombosis (including recurrent tricuspid prosthetic valve thrombosis and Ebstein's anomaly).[29-32]
INNOVATION No. 2: BROAD PRE-HOSPITAL USE OF STREPTOKINASE

In 2002, the WHO reported that in developed and developing countries alike, 40-75 percent of all AMI victims die before reaching the hospital.[33] Today, the percentage of those dying before reaching medical attention is estimated to be at least 50\%.[4]

As time is of the essence, the updated American College of Cardiology/American Heart Association guidelines recommend that primary $\mathrm{PCl}$ be performed within 90 minutes of onset of symptoms and a thrombolytic agent be administered within 30 minutes.[34] To respond to AMI at a population level, two main strategies can be used, depending on the local context: bringing the patient to treatment (bringing the patient in a timely manner to a clinical setting where thrombolysis is available or to a catheterization laboratory for primary angiography), or bringing treatment closer to the patient (performing thrombolysis in a prehospital setting). Either strategy assumes a generally developed infrastructure: a functional healthcare delivery system, availability of thrombolytics and/or an accessible catheterization laboratory, plus trained personnel.

Around the world, several models have been designed to improve AMI patient outcomes by improving the provision of timely and effective care. However, these have mostly been implemented in the developed world (France; City of Vienna, Austria; Mayo Clinic regional network, USA, etc.).[35] The question remains: what would a system of improved care for AMI patients look like in a developing country?

Based on a single universal public health system founded on strong primary health care, the potential for training personnel at the local level, availability of domestically produced recombinant streptokinase, and experiences such as those in Cienfuegos Province, Cuban health authorities decided to generate a model to bring treatment to AMI patients in pre-hospital settings. The model as a 'work in progress' reveals the interface among the various levels of care and the emergency system in pursuit of three overarching goals: increased coverage, geographical access and quality of care.

At the heart of this model is the Integrated Medical Emergency System (SIUM, its Spanish acronym), organized into municipal, provincial and specialty care subsystems. The municipal subsystem is anchored in primary care, specifically in the urgent care polyclinics around the country-specially designated from among the nearly 500 community-based polyclinics dispersed throughout Cuban municipalities that serve a geographically defined population. Each urgent care polyclinic has a municipal Intensive Care Unit (ICU) and hosts a local coordinating center responsible for municipal ambulance dispatch.

The provincial subsystem includes a provincial coordinating center and intensive-care ambulance dispatch, and is designed to oversee the flow of severely ill patients and coordinate medical care with other sectors in accidents and disaster situations. The third subsystem operates through hospital emergency rooms and units of intensive and intermediate care.[36,37]

Dr Ricardo Pereda, deputy director of SIUM's national coordinating center, notes that the AMI initiative began as a pilot 
program in the late 1990 s, in which trained ambulance personnel went to polyclinics to conduct thrombolysis. Later, municipal Intensive Care Units were equipped and their own personnel trained in the procedure. "The rationale was to bring the services closer to the population in order to reduce the time between symptom onset, diagnosis and treatment," explained Dr Pereda. The current nationwide AMI care system has been in place since the end of 2003. Today there are 121 municipal ICUs across the country; approximately 8 per province (10 in Havana City Province).

The system relies on AMI diagnosis and initial treatment at the local Unit, then on coordination with SIUM for patient transport to the corre-

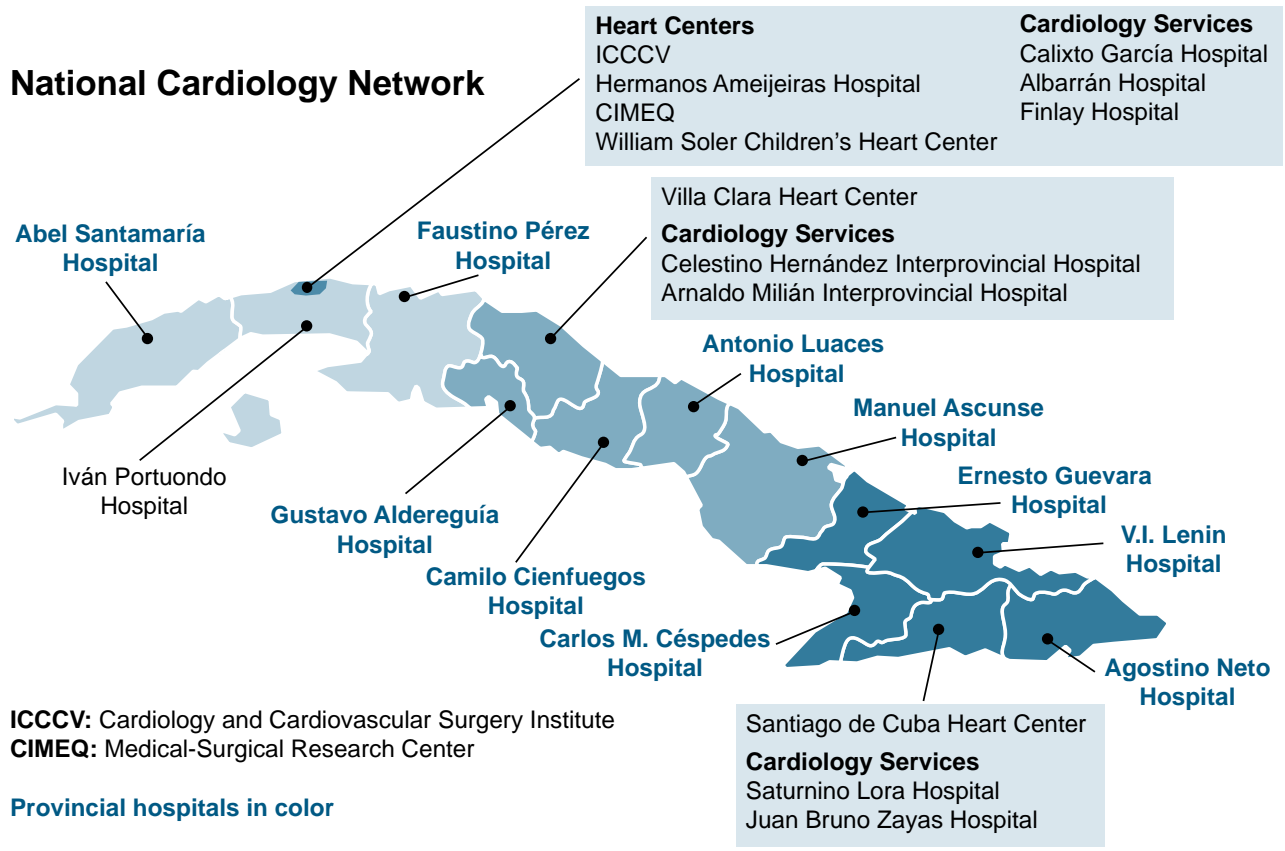
sponding hospital ICU. Dr Pereda describes the likely trajectory of a patient presenting with AMI symptoms at home: "A person experiencing chest pain may contact his/her family doctor or, more frequently, be taken by the family to the nearest polyclinic, which is usually about 10 minutes away. If this is one of the main urgent care polyclinics with a municipal ICU, then the patient will be seen by a primary care specialist trained to diagnose an AMI and conduct thrombolysis in eligible patients. Diagnosis is made by clinical exam and electrocardiogram; in some areas, enzyme testing is also conducted. If the polyclinic is not an urgent care facility, then transport is arranged, either to the nearest one or to a hospital, depending on the specifics of the patient's situation and distances involved."

Dr Luis Collazo, SIUM provincial director for Havana City, notes that transferring a procedure such as thrombolysis to the primary care level has had a significant impact on patient care. "Let's take a concrete example: A patient in the Santa Fe municipality of Havana City Province would decrease time from 'door-to-needle' by at least 40 minutes, since it takes at least 20 minutes to reach the nearest hospital, and at least another 20 minutes for re-evaluation at the emergency room, not to mention the 20 minutes of preparation for thrombolysis itself...As we say, 'time is myocardium;' therefore, time saved is myocardium saved."

According to SIUM records, from January 2004, when this strategy became fully operational, through December 2009, 9195 AMI patients were registered nationwide, and 4149 received thrombolysis in municipal ICUs, for a $45.1 \%$ thrombolysis rate. Preliminary SIUM data analysis shows a a lethality rate of $8.7 \% .[36,38]$

\section{INNOVATION No. 3:}

\section{A NATIONAL CARDIOLOGY NETWORK}

Cuba's national cardiology and cardiovascular surgery network, in place since 2003, aims to improve quality of care for heart patients by improving coordination among all levels of health services, according to Dr Lorenzo Llerena, director of

the Cardiology and Cardiovascular Surgery Institute (ICCCV, its Spanish acronym) in Havana. Dr Llerena describes it as "a model for achieving greater equity in health service delivery, since a patient anywhere in the country can be identified, diagnosed and referred to the best place for specialized treatment," adding that "the point is to increase accessibility to services, even among people living in rural areas, since equity is reached only when there is total coverage. And this is what we have tried to do through the clinical network in conjunction with the emergency system."

The clinical network also reinforces uniformity in treatment protocols and encourages closer collaboration among the different levels of care. It links heart centers and selected hospitals throughout the country, including lead centers by region: the Santiago de Cuba Heart Center in the east; Villa Clara Heart Center in the central region; and the ICCCV, Ameijeiras Hospital, Carlos J. Finlay Hospital, Medical-Surgical Research Center, and William Soler Children's Heart Center in the west. Core institutions now total 18 hospitals and 6 heart centers (see map). Provincial network coordinators establish links with community-based family doctors, polyclinics and hospitals, and gather information related to cardiovascular care, procedures and mortality.

The network has seven sub-programs: arrhythmias and pacemakers, cardiovascular surgery, interventionist cardiology, general cardiology (intensive care units), ambulatory and diagnostic services, rehabilitation, and specialized services. In addition to coordinating clinical patient care, the network monitors treatment protocols and outcomes; certain patients, such as those with pacemakers and defibrillators; human resources needs and training; and equipment and supply needs; among other aspects of cardiology development in the public health system.

The potential is even greater, explains Dr Caridad Kesser, epidemiologist at the ICCCV's network coordinating office. She notes one of the main goals now is to fully develop a common 
database to monitor the number and type of cardiovascular procedures conducted in each subprogram, including thrombolysis, coronarography, angioplasty, valvuloplasty, and physical therapy. For AMI management, in particular, a network data collection system is being built to evaluate use of reperfusion therapy in patients throughout the country.

Cardiology network hospitals and heart centers receive AMI patients directly in their emergency rooms or transferred from other hospitals or from polyclinics. From 2004 to 2008, network institutions admitted 20,259 AMI patients, 8624 of whom received thrombolysis, with an average annual lethality rate of $6.8 \%$. The share of patients receiving thrombolysis has climbed from $37.8 \%$ in 2004 to $61 \%$ in 2008.[38,39]

In the absence of a comprehensive national AMI registry, each of the two interfacing AMI patient care systems (SIUM and the cardiology network) maintains its own records, resulting in overlap. "However, available data suggest that the thrombolysis rate in the country stands at about 56\%", notes Dr Llerena, adding that this is not optimal. There are also regional differences: in 2007, the thrombolysis rate was highest in the central region (61\%) and lower for the western and eastern regions (both 54\%). There are no global figures reflecting international reperfusion rates; limited data from the Global Registry of Acute Coronary Events (GRACE) shows a combined thrombolysis and $\mathrm{PCl}$ rate of $60 \%$ in 94 hospitals in 14 countries of Europe, the Americas, Australia and New Zealand.[40]

Emergency care for AMI patients is only one end of a continuum, stresses Dr Reynaldo de la Noval at ICCCV. "Secondary prevention, including smoking cessation counseling, medications like beta-blockers, education on healthy eating and physi-

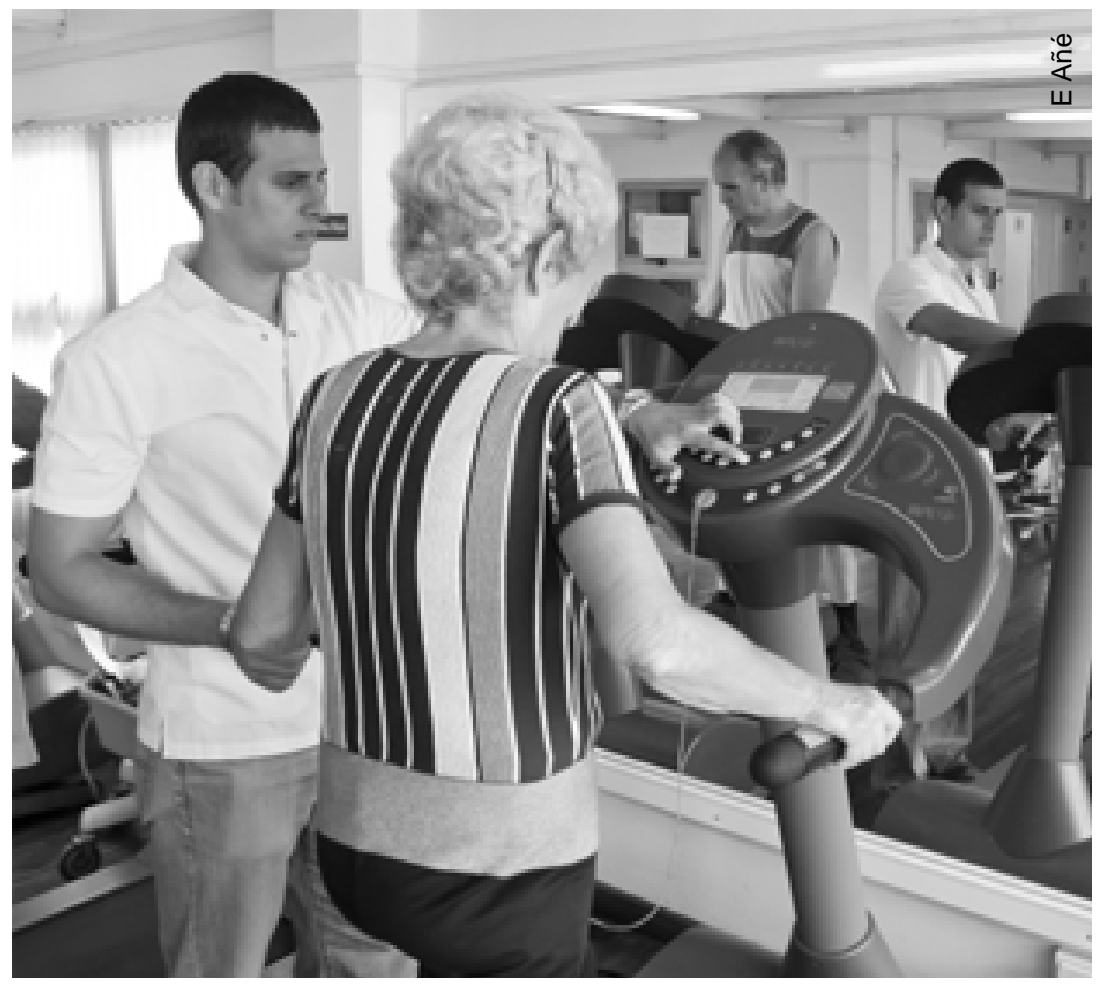

ICCCV rehabilitation services, Havana. cal activity-all are part of follow-up offered by a multidisciplinary team assigned to each patient, including a psychologist, a nutritionist and rehabilitation cardiologist." Cardiac rehabilitation seeks to "increase the functional capacity of the patients, reduce unnecessary physical limitations and facilitate return of heart patients to a productive and satisfying life," explains $\mathrm{Dr}$ Eduardo Rivas of the ICCCV's rehabilitation services. These services are available at the heart centers, hospitals and also in community-based polyclinic physical therapy units.

\section{CHALLENGES}

Evidence suggests that the strategies in place in Cuba are reducing AMI lethality, which has declined for adults aged $>25$ years from $56.9 \%$ in $1999-2004$ to $51.8 \%$ in $2004-2008$.[11] However, in addition to the ever-present need to streamline the interface among all levels of care, the network and SIUM, leaders in the field identify four challenges requiring special attention:

1) Increase use of reperfusion therapy in eligible patients, especially in primary health care services.

2) Focus on training and public education at the community level.

3) Implement more effective prevention strategies.

4) Improve monitoring and research capacities through a national AMI registry.

Although primary angioplasty is the preferred option for AMI patients in highly developed countries, full access to this procedure remains difficult because of geographic and/or health system constraints. In Cuba, conditions are permitting gradually more coronary angioplasties. From 2002 to 2008, 900 AMI patients received percutaneous transluminal coronary angioplasties (PTCA), with numbers rising annually in Havana as well as in provincial heart centers.[39]

"Despite this progress," Dr Llerena emphasizes, "thrombolysis will continue to be the treatment of choice in most places lacking facilities and specialized personnel." Consequently, he says, emphasis must be placed on achieving better thrombolysis rates, especially in municipal ICUs, noting that "the battle against time in an AMI has to be won by early diagnosis and rapid reperfusion at the primary care level."

The second challenge is also in primary care: continuous training and retraining of personnel in municipal ICUs is paramount, given staff turnover and the relatively infrequent need to perform thrombolysis. Public education also begins here. This is essential at the community level in order for residents to effectively recognize early AMI symptoms and understand the need to gain precious time to improve chances of survival.

However, "the greatest challenge is prevention," says Dr Alfredo Dueñas, director of preventive cardiology at the ICCCV. "Lower lethality is the result of improvements in medical care and the delivery system. We need to maintain those measures be- 
cause we cannot lower incidence from one day to the next," he observes. "However, we need to work much harder on tobacco control, promotion and increased access to healthy foods and physical activity, along with hypertension control. The country cannot expect major changes in incidence without such prevention." Indeed, international cardiovascular disease experts concur that a significant decline in disease burden requires public health approaches at the policy, social and personal levels, especially in tobacco control and obesity reduction.[41]

Finally, creation of a national AMI registry is on the agenda. Several developed countries have national registries, but these are practically non-existent in the developing world.[17] In Cuba, a registry is key to providing the comprehensive data required for large epidemiological studies needed to reveal trends in lethality and mortality rates, and to assess the impact of current strategies. According to Dr Llerena, a proposal has been submitted to the Ministry of Public Health to make AMI a reportable condition, laying the basis for the registry.

Cuba has shown creativity in implementing a promising strategy for AMI management in a global context in which options for developing-country patients most often range from timely reperfusion therapy available to relatively few, to beta blockers or aspirin, or no treatment at all. Cuba's approach to AMI patient care seeks to promote appropriate responses starting at the community level with informed patients, to primary care physicians trained and prepared to conduct thrombolysis at municipal ICUs, to emergency responders and specialists at hospitals and heart centers. Despite the challenges, the Cuban model merits attention, since it represents combining developing-country biotechnology with an approach that makes effective care more accessible, and more thoroughly integrated at all levels of the health system. $\mu$ -

\section{References \& Notes}

1. Mackay J, Mensah G. The Atlas of Heart Disease and Stroke. [Internet]. Geneva: World Health Organization; 2004. Types of Cardiovascular Disease; [cited 2010 May 15]; p. 18. Available from: http://www.who.int/cardiovascular_diseases/en/cvd_atlas_01_types.pdf

2. Mathers CD, Boerma T, Ma Fat D. Global and regional causes of death. $\mathrm{Br}$ Med Bull. 2009;92:7-32.

3. Mathers CD, Loncar D. Projections of global mortality and burden of disease from 2002 to 2030. PLoS Medicine. 2006 Nov;3(11):e442.

4. Gaziano TA, Bitton A, Anand S, Abrahams-Gessel S, Murphy A. Growing epidemic of coronary heart disease in low- and middle-income countries. Curr Probl Cardiol. 2010;35(2):72-115.

5. Gaziano TA. Cardiovascular disease in the developing world and its costeffective management. Cardiology Rounds [Internet]. 2005 Feb [cited 2010 May 27];9(2) 6 p. Available from: http://www.cardiologyrounds.org/crus/cardious 0205.pdf

6. Armas N, Hernández Y, Dueñas A, de la Noval R, Castillo A. Cardiovascular Risk among Older Women in a Havana Health Area. MEDICC Rev. 2008;10(2):21-6.

7. Cooper RS, Orduñez P, Iraola Ferrer MD, Munoz JL, Espinosa-Brito A. Cardiovascular disease and associated risk factors in Cuba: prospects for prevention and control. Am J Public Health. 2006;96(1):94-101.

8. Reed G. Chronic Vascular Diseases in Cuba: Strategies for 2015. MEDICC Rev. 2008;10(2):5-7.

9. Franco M, Orduñez P, Caballero B, Tapia Granados JA, Lazo M, Bernal JL, et al. Impact of energy intake, physical activity, and population-wide weight loss on cardiovascular disease and diabetes mortality in Cuba, 1980-2005. Am J Epidemiol. 2007;166(12):1374-80.

10. Hernández A, Dueñas A, Llerena L. Programa nacional de prevención, diagnóstico, evaluación, tratamiento y rehabilitación de la cardiopatía isquémica. República de Cuba. Havana: Ministry of Public Health (CU); 2000. 39 p.

11. Interviews conducted with Dr Lorenzo Llerena, Dr Alfredo Dueñas, Dr Nurys Armas, Dr Reynaldo de la Noval and Dr Yanela Ortega at Department of Preventive Cardiology, Cardiology and Cardiovascular Surgery Institute. Havana, Cuba. March 8-12, 2010.

12. Fernández A, Gálvez AM, Castillo A. Costo institucional del infarto agudo del miocardio en el Instituto de Cardiología y Cirugía Cardiovascular. Rev Cubana de Salud Pública. 2008;34(4):8.

13. Cabrera JO, Palacio H. Factores asociados a mortalidad intrahospitalaria en el infarto agudo del miocardio con supradesnivel del ST. Rev Cubana Invest Biomed. 2008 Jan-Mar;27(1):1-10.

14. Based on the range of the ST segment elevation visible in the electrocardiogram, there are two main types of AMI: with ST elevation (STEMI) and without (NSTEMI). STEMI is a severe infarct caused by a prolonged blockage of the blood supply and affecting a large area of the heart, posing substantial risk of death and disability. Each type of AMI has its own separate and distinct treatment guidelines and STEMI is the type of infarct that benefits the most from immediate reperfusion therapy.

15. Fox KA, Steg PG, Eagle KA, Goodman SG, Anderson FA Jr, Granger CB, et al. Decline in rates of death and heart failure in acute coronary syndromes, 1999-2006. JAMA. 2007;297(17):1892-900.

16. The American College of Cardiology, the American Heart Association and the European Society of Cardiology endorse reperfusion as a class 1 recommendation, signifying sufficient evidence that the treatment is beneficial, useful and effective. See ref. 19 and 34.
17. Abdallah $\mathrm{MH}$, Arnaout S, Karrowni W, Dakik HA. The management of acute myocardial infarction in developing countries. Int $\mathrm{J}$ Cardiol. 2006;111(2):189-94.

18. Sikri N, Bardia A. A history of streptokinase use in acute myocardial infarction. Tex Heart Inst J. 2007;34(3):318-27.

19. Van de Werf $F$, Bax J, Betriu A, Blomstrom-Lundqvist $C$, Crea F, Falk V et al. Management of acute myocardial infarction in patients presenting with persistent ST-segment elevation: The Task Force on the management of STsegment elevation acute myocardial infarction of the European Society of Cardiology. Eur Heart J. 2008;29(23):2909-45.

20. Walley T, Dundar Y, Hill R, Dickson R. Superiority and equivalence in thrombolytic drugs: an interpretation. QJM. 2003 Feb;96(2):155-60.

21. Nazzal NC, Campos TP, Corbalán HR, Lanas ZF, Bartolucci JJ, Sanhueza CP, et al. The impact of Chilean health reform in the management and mortality of ST elevation myocardial infarction (STEMI) in Chilean hospitals. Rev Med Chil. 2008 Oct;136(10):1231-9.

22. Raffo C, Bartolucci J, Corbalán R, Aninat M, Torres H, Prieto JC, et al. Utilidad de la terapia trombolítica con estreptokinasa a dosis baja en infarto agudo del miocardio. Rev Med Chil. 2006;134(10):1249-57.

23. Hermentin P, Cuesta-Linker T, Weisse J, Schmidt K, Knorst M, Scheld M, et al. Comparative analysis of the activity and content of different streptokinase preparations. Eur Heart J. 2005 May;26(9):933-40.

24. At the time of the study, Streptase was registered with Hoeschst-Roussel, Germany; today Aventis, Behring $\mathrm{GmbH}$, Germany.

25. The TERIMA Group Investigators. Multicenter, randomised, comparative study of recombinant vs. natural streptokinases in acute myocardial infarct. Thromb Haemost. 1999;82:1605-9.

26. The TERIMA Group of Investigators. TERIMA-2: national extension of thrombolytic treatment with recombinant streptokinase in acute myocardial infarct in Cuba. Thromb Haemost. 2000;84:949-54.

27. Betancourt BY, Marrero-Miragaya MA, Jiménez-López G, Valenzuela-Silva C, García-Iglesias E, Hernández-Bernal F, et al. Pharmacovigilance program to monitor adverse reactions of recombinant streptokinase in acute myocardial infarction. BMC Clin Pharmacol. 2005 Nov 2;5:5.

28. Pérez-Oliva JF, Parodis Y, Benitez O, Sotolongo R, Vigoa ME, Raola ME, et al Use of Recombinant streptokinase for hemodialysis catheter recovery. MEDICC Rev. 2005;7(5):24-6.

29. Cáceres-Lóriga FM, Pérez-López H, Santos-Gracia J, Morlans-Hernandez K. Prosthetic heart valve thrombosis: pathogenesis, diagnosis and management. Int J Cardiol. 2006 Jun 7;110(1):1-6.

30. Cáceres-Lóriga FM, Pérez-López H, Morlans-Hernández K, Facundo-Sánchez $\mathrm{H}$, Santos-Gracia J, Valiente-Mustelier J, et al. Thrombolysis as first choice therapy in prosthetic heart valve thrombosis. A study of 68 patients. J Thromb Thrombolysis. 2006 Apr;21(2):185-90.

31. Cáceres-Lóriga FM, Santos-Gracia J, Pérez-López H. Thrombotic obstruction of a mechanical prosthetic valve in tricuspid position: therapeutic considerations. Tex Heart Inst J. 2009;36(5):505.

32. Cáceres-Lóriga FM, Pérez-López H, Santos-Gracia J, Morlans-Hernández K, Marrero-Mirayaga MA. Thrombolytic treatment as first option in recurrent tricuspid prosthetic valve thrombosis and Ebstein's anomaly. J Pharm Pharm Sci. 2005;8(2):332-4

33. World Health Organization. Integrated Management of Cardiovascular Risk Report of WHO Meeting, Geneva, July 2002. Non-communicable Diseases 
and Mental Health [Internet]. 2002 [cited 2010 Jun 28]. 44p. Available from whqlibdoc.who.int/publications/9241562242.pdf

34. Antman EM, Hand M, Armstrong PW, Bates ER, Green LA, Halasyamani LK et al. 2007 Focused update of the ACC/AHA 2004 guidelines for the management of patients with ST-elevation myocardial infarction: a report of the American College of Cardiology/American Heart Association Task Force on Practice Guidelines. Circulation. 2008 Jan 15;117(2):296-329.

35. Danchin N. Systems of care for ST-segment elevation myocardial infarction: impact of different models on clinical outcomes. J Am Coll Cardiol Intv. 2009;2(10):901-8.

36. Interview with Dr Ricardo Pereda, deputy director SIUM, Havana, Cuba. May 28,2010

37. Sosa A. Organización, estructura y dirección de la urgencia de los cuidados intensivos. In: Caballero A, editor. Terapia intensiva. Tomo I [Internet] Havana: Editorial Ciencias Médicas; c2006 [cited 2010 May 15]. [about 13 p.]. Available from: http://www.bvs.sld.cu/libros_texto/terapia_intensiva/capitulo03 nuevo.pdf
38. These are crude estimates prepared for operational reporting. The epidemiology of AMI is very complex and several challenges have been identified among others: 1 . Changing definition of MI, 2. Pervasive grouping of ST elevation MI and non-ST elevation into the single category of MI, 3. Difficulty assessing population denominators. See Yeh RW, Go AS. Rethinking the Epidemiology of Acute Myocardial Infarction. Challenges and Opportunities. Arch Intern Med. 2010;170(9):759-64

39. Interview with Dr Caridad Kesser, epidemiologist, ICCCV, Havana, Cuba, February 15, 2010.

40. Eagle KA, Goodman SG, Avezum A, Budaj A, Sullivan CM, LópezSendón $\mathrm{J}$, et al. Practice variation and missed opportunities for reperfusion in ST-segment-elevation myocardial infarction: findings from the Global Registry of Acute Coronary Events (GRACE). Lancet. 2002;359(9304):373-7.

41. Vartiainen E, Laatikainen T, Peltonen M, Juolevi A, Männistö S, Sundvall J, et al. Thirty-five-year trends in cardiovascular risk factors in Finland. Int J Epidemiol. 2010;39(2):504-18.

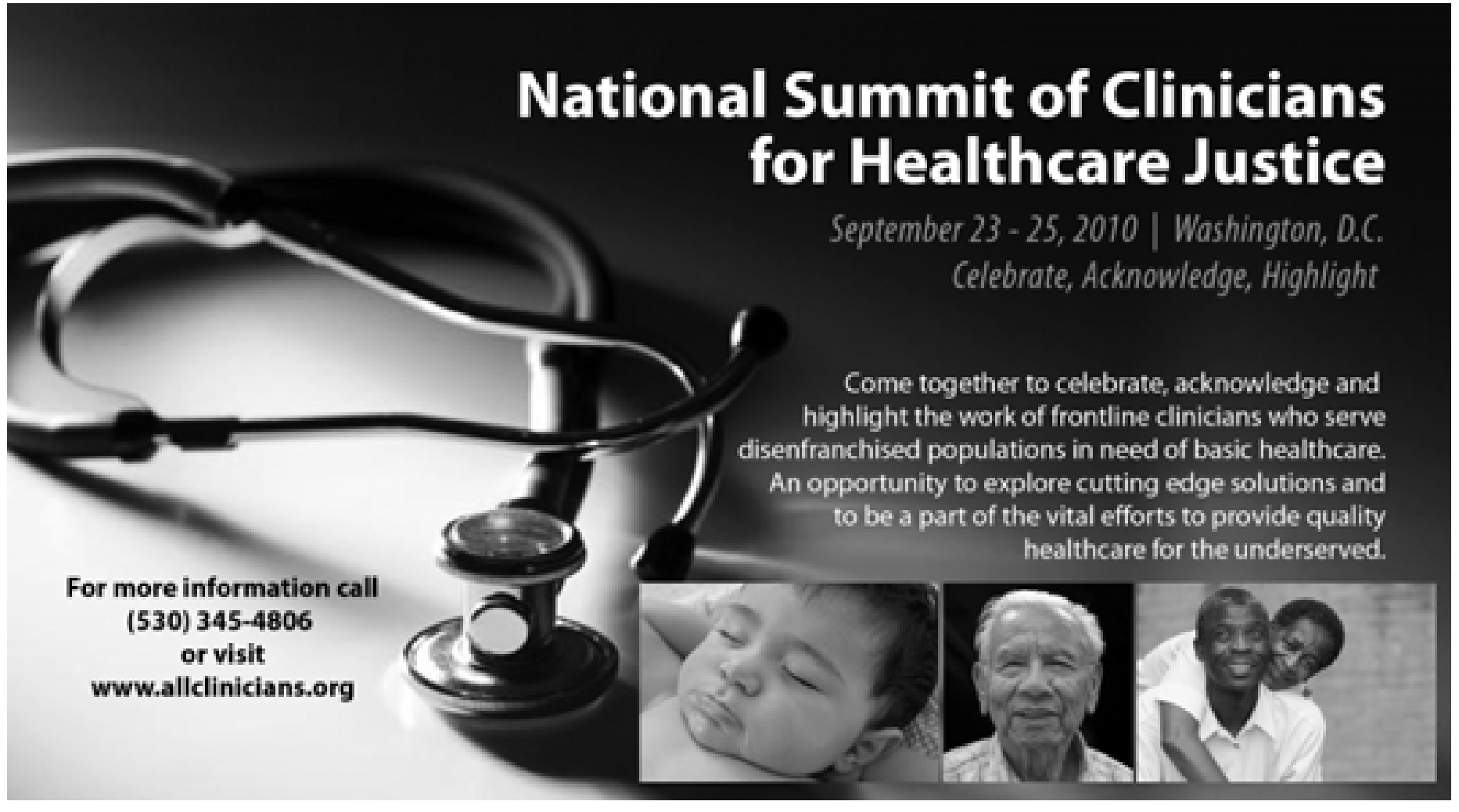

